\title{
Two Novel Human Anti-cd25 Antibodies With Antitumor Activity Inversely Related to Its Affinity and in Vitro Activity
}

\section{Deyong Song}

Shandong Boan Biotechnology Co., Ltd.

\section{Xiu Liu}

Shandong Boan Biotechnology Co., Ltd.

\section{Chuangchuang Dong}

Shandong Boan Biotechnology Co., Ltd.

Chunjie Sha

Shandong Luye Pharmaceutical Co. Ltd.

\section{Zhenfei Ning}

Shandong Boan Biotechnology Co., Ltd.

\section{Qiaoping Wang}

Shandong Boan Biotechnology Co., Ltd.

Jing Han

Shandong Boan Biotechnology Co., Ltd.

Hong Liu

Shandong Boan Biotechnology Co., Ltd.

Hongguang $\mathrm{Xu}$

Shandong Boan Biotechnology Co., Ltd.

Huimin Zhang

Shandong Boan Biotechnology Co., Ltd.

\section{Pingping Xing}

Shandong Boan Biotechnology Co., Ltd.

\section{Mengqi Zong}

Shandong Boan Biotechnology Co., Ltd.

\section{Ying Li}

Shandong Boan Biotechnology Co., Ltd.

\section{Guangsheng Liu}

Shandong Boan Biotechnology Co., Ltd.

\section{Xin Shao}

Shandong Luye Pharmaceutical Co. Ltd.

Changlin Dou ( $\nabla$ douchanglin@luye.com ) 
Shandong Boan Biotechnology Co., Ltd.

\section{Research Article}

Keywords: High tumor regulatory T (Treg), BT942, Treg cells, cytotoxic activity, toxicity efficacy

Posted Date: March 12th, 2021

DOl: https://doi.org/10.21203/rs.3.rs-277192/v1

License: (c) (i) This work is licensed under a Creative Commons Attribution 4.0 International License. Read Full License 


\section{Abstract}

High tumor regulatory $\mathrm{T}$ (Treg) cell infiltration is associated with poor prognosis of many cancers. CD25 is highly expressed on tumor Treg cells and is a potential target for Treg deletion. Previously characterized anti-CD25 antibodies appear to have limited efficacy. Here we identified two human antiCD25 antibodies, BA9 and BT942, which demonstrated strong tumor growth inhibition in both early and late-stage animal cancer models. BT942 had weaker binding and cytotoxic activity to human CD25expressing cell lines than BA9. But BT942 showed a stronger anti-tumor effect and resulted a higher expansion of $C D 8^{+} T$ cells and $C D 4^{+} T$ cells in tumor microenvironment at the mouse MC38 model compared to BA9. As CD25 is transiently expressed on activated Teff cells, it is likely that BT942 with lower affinity can distinguish high expression Treg and low expression Teff and therefore cannot kill Teff cells effectively. Such a combination of BT942's abilities may underline its stronger effect. BT942 also demonstrated higher tumor growth inhibition in combination with an anti-PD1 antibody. Pharmacokinetic tests of BT942 in cynomolgus monkey demonstrated a half-life of $206.97 \pm 19.03$ hours. No toxicity efficacy was seen in mice efficacy or monkey examinations. BT942 appears to be an excellent candidate for cancer immunotherapy.

\section{Introduction}

In humans, regulatory $\mathrm{T}$ (Treg) cell population accounts for only $5 \%$ of $\mathrm{CD} 4^{+} \mathrm{T}$ cells, which are characterized by constitutively high expression of CD25 and immune suppression ${ }^{1,2}$. There are two subgroups of Tregs: the naturally occurring Treg cells (nTregs) and the inducible or adaptive Tregs (iTreg, Tr1). nTregs and iTregs mediate their suppression via cell contact-dependent mechanisms or through the production of soluble factors, such as TGF-beta, IL-10 and adenosine ${ }^{3,4}$. Removal of CD $25^{+} C D 4^{+} T$ cells cause several autoimmune diseases in mice ${ }^{5,6}$.

The number of Treg cells is higher in peripheral blood mononuclear cells (PBMC) of many cancer patients, especially in tumors ${ }^{7-11}$. Treg cells can suppress most immune cells including CD $4^{+}$and $C D 8^{+} T$ cells, B cells, NK cells, NKT cells and APCs, such as DCs, monocytes and macrophages $(3,4)$. High Treg infiltration is related to the poor prognosis of most solid tumors, such as cervical, ovarian, renal, melanomas, pancreatic, hepatocellular, gastric and breast cancers ${ }^{12-18}$. Recent systematic review and meta-analysis on FoxP3 ${ }^{+}$Treg cells revealed that prognostic role of Fox $3^{+}$Tregs was highly influenced by tumor site and was also correlated with the molecular subtype and tumor stage ${ }^{12}$. Removing $\mathrm{CD} 25^{+} \mathrm{CD} 4^{+} \mathrm{T}$ cells or in vivo administration of anti-CD25 (interleukin-2 receptor alpha) monoclonal antibody in mice can induced tumor immunity or tumor suppression ${ }^{19-21}$. Consequently, Treg deletion from the tumor should be beneficial for tumor treatment. Removing Tregs is likely to increase the response rate of current immunotherapy by relieving Treg cell inhibition on Teff cells, B cells and NK cells in the tumor microenvironment. 
There are several targets on Treg cells, in addition to antibodies targeting CD25, Smyth and colleagues ${ }^{22}$ revealed that antibodies against other targets such as CTLA4, OX40 and GITR may facilitate the elimination of regulatory $T$ cells in the tumor microenvironment by the effector functions of the antibody 22-25. Such antibody-mediated killing of regulatory $T$ cells may be more important than the antibodymediated activation of effector $T$ cells for the anti-tumor activities of those antibodies. However, among those targets, CD25 (interleukin-2 high affinity receptor alpha chain, IL-2Ra) is expressed at high level. Also, CD25 antibodies not only significantly reduce Treg cells, but also greatly increase the effector $\mathrm{T}$ cell populations in tumors. CD25 is one of the potential molecular targets for Treg-targeting therapy.

Although in vitro studies have confirmed that CD25 is transiently upregulated after Teff cells are activated 26 , the studies in mouse models show that both the expression percentage and the level of expression of CD25 in Teff cells are much lower than Treg cells in tumor ${ }^{19}$. In human cancers, CD25 is mainly expressed on $\mathrm{CD}^{+}{ }^{+} \mathrm{FoxP}^{+}$Treg cells and in all tumor types studied, the level of CD25 expression in $\mathrm{CD}^{+}{ }^{+} \mathrm{FoxP}^{+}$Treg cells is also significantly higher than that in $\mathrm{CD}^{+}{ }^{+} \mathrm{FoxP} 3^{-}$and $\mathrm{CD} 8^{+} \mathrm{T}$ cells ${ }^{27}$.

Several anti-CD25 antibodies had been developed. Anti-CD25 monoclonal antibodies (clone PC61, rat IgG1) can only be effective when injected before tumor inoculation or early tumor establishment. Specifically, in mice MOPC-70A models, it can only be effective when administered before day 2 after tumor inoculation ${ }^{20}$. In the mouse A20 model, anti-CD25 monoclonal antibodies (PC61) could not inhibit tumor growth administering when the tumor was palpable ${ }^{19}$. Arce Vargas and colleagues ${ }^{27}$ analyzed why the anti-CD25(clone PC61, rat IgG1) has only the limited effect in mice. Their results shown that the high expression of FcRIlb and inappropriate Fc of anti-CD25 resulted in the invalid clearance of Treg in the tumor. Fc-Optimized Anti-CD25 (clone PC61, murine IgG2a) showed a good effect in the established MC38, MCA205, CD26 model in combination with anti-mouse PD1. This Fc-Optimized Anti-CD25 (Clone PC61, murine IgG2a) has good efficacy at the combination group, but the efficacy of single anti-CD25 administration was weak 27 .

The therapeutic potential of targeting CD25 led us to develop a screening strategy to identify potent human antibodies against CD25. Using immunized human antibody mice and phage display we identified two human BA9 and BT942 monoclonal antibodies that target CD25. In addition, we provide evidence that both BA9 and BT942 display significant binding activity to CD25 and that they do not prevent the activation of downstream signaling pathway. Furthermore, we show that BA9 and BT942 have significant cell-mediated cytotoxicity and tumor suppression in both early phase and late phase of tumor establishment. Finally, we provide evidence that BT942 appears more potent in vivo than BA9 with the ability to synergize with anti-PD1 inhibitor.

\section{Methods}

\section{Mice, cell lines and reagents}

Reagents, cell lines and viral strains used in this study are listed in Supplementary Table 1. 


\section{Generation of CD25 antibodies}

The mice used for immunization are human antibody transgenic mice that generated by our company. They were bred and kept under specific-pathogen free conditions. All animal experiments were complied with relevant ethical regulations regarding animal research. Protocols of mice experiments for immunization were approved by LUYE PHARMA Animal Experimentation and Ethics Committee. Human antibody transgenic mice were sequentially immunized with CD25. In the meantime, titers of antibodies in the mice serum were tested by ELISA. Three days after the last immunization, the spleen was harvested for library construction. The construct of the phage library was carried out according to the method described in Phage Display: A laboratory manua ${ }^{29}$. Plates coated with CD25 or streptavidin- magnetic beads binding biotin-CD25 were used to capture interest phages. Enriched phages were used to infect $E$. coli TG1 for expressing single-chain variable fragments (scFvs) and the binding and blocking activity were tested by ELISA. Positive clones were obtained and sequenced.

\section{Antibodies production}

Heavy chain variable region and light chain variable region were amplified $(2 \times$ Phanta Max Master Mix, Vazyme, P515-01) using the positive clones screened from the library as templates. Overlap PCR was conducted to assemble variable region and signal peptide. Purified gene fragments were separately fused (ClonExpress II One Step Cloning Kit, Vazyme, C112-01) into the linearized pcDNA3.4 vectors with constant regions. The recombinant plasmids were prepared for production. Antibodies were expressed with Expi-CHO Expression system (A29133, Gibco) for 12days and the supernatants were harvested and purified by a AT Protein A Diamond (AA0272, Bestchrom).

\section{ELISA - based binding assay}

CD25 protein (10165-H08H, Sino Biological) was coated on high binding ELISA plates with $0.2 \mu \mathrm{g} / \mathrm{mL}$ at $4^{\circ} \mathrm{C}$ overnight, and then the plates were blocked with $3 \%$ skim milk powder in PBST (PBS containing $0.05 \%$ Tween-20) at $37^{\circ} \mathrm{C}$ for 1 hour. After washing two times with PBST, serially diluted antibodies were added to each well, incubated at $37^{\circ} \mathrm{C}$ for $1 \mathrm{~h}$. Plates were washed two times and then HRP-goat antihuman IgG mAb (474-1006, KPL) was used to detect antibodies binding to CD25. Experiments were performed in triplicate, value=Mean \pm SEM.

\section{Cell based binding assay}

SU-DHL-1(CRL-2955, ATCC) or HEK293T-CD25 cells were harvested and washed by FACS buffer $(0.2 \%$ BSA in PBS) two times. Serially diluted antibodies were mixed with $1 \times 10^{6}$ cells at $4^{\circ} \mathrm{C}$ for 1 hour. After washing two times by FACS buffer, cells were incubated in dark with Goat Anti-Human IgG-PE (2040-09, Southern Biotech) at $4{ }^{\circ} \mathrm{C}$ for $30 \mathrm{~min}$ and then analyzed by NovoCyte 2060R flow cytometry. Experiments were performed in triplicate, value $=$ Mean \pm SEM.

\section{ADCC reporter bioassay}


ADCC reporter bioassay was conducted with SU-DHL-1 cells, HEK293T-CD25 cells or CD8 ${ }^{+} \mathrm{T}$ cells as target cells and Jurkat cells (G7011, Promega) as effector cells. Activated CD8 ${ }^{+} \mathrm{T}$ cells were got by stimulating $\mathrm{CD}^{+}{ }^{+}$cells for 72 hours with OKT3, CD28 antibody and IL-2. $25 \mu \mathrm{L}$ target cells at $1.2 \mathrm{E} 6 / \mathrm{mL}$, serially diluted antibodies and Jurkat cells at $2.4 \mathrm{E} 6 / \mathrm{mL}$ were sequentially added to a White Tissue Culture treated 96 well plate in a cell incubator for 5 hours. Bio-Glo Luciferase Assay Buffer/Substrate (G7940, Promega) was added to react for $15 \mathrm{~min}$ and then the value of Luminescence was read on Tecan microplate reader. Experiments were performed in duplicate, value=Mean \pm SEM.

\section{In vitro ADCC assay}

Antibody-dependent cell-mediated cytotoxicity was conducted with SU-DHL-1 cells, inactivated CD8+ T (PB009-3-C, ALLCELLS) cells or activated CD8+T cells as target cells and PBMCs as effector cells. Activated CD8+ T cells were got by stimulating CD8+ T cells for 72 hours with OKT3, CD28 antibody and IL-2. Serially diluted antibodies were mixed with target cells in $96-$ well plates at $37^{\circ} \mathrm{C}$ for $15-30$ minutes. The effector cells PBMCs (PB003F-C, ALLCELLS) were added and the mixture was incubated at $37^{\circ} \mathrm{C}$ for 5 hours. After substrate was added, OD490 value was read on the microplate reader. Percent cytotoxicity

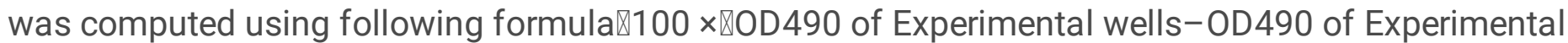

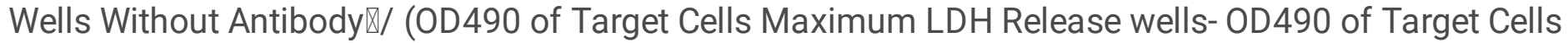
Spontaneous LDH Release wells). Experiments were performed in duplicate, value=Mean \pm SEM.

\section{Affinity analysis by Surface Plasmon Resonance}

SPR measurements were performed at room temperature using a BIAcore $8 \mathrm{~K}$ system with CM5 chip, which was amino coupled by human antibody capture kit. HBS-EP+ buffer $(150 \mathrm{mM} \mathrm{NaCl}, 10 \mathrm{mM}$ HEPES, $3 \mathrm{mM}$ EDTA and $0.05 \%(\mathrm{v} / \mathrm{v})$ surfactant P20 pH 7.4) was used as running buffer. The blank channel of the chip served as the negative control. The antibodies were captured on the chip at 400-500 response units. Serial dilutions of CD25 (from $50 \mathrm{nM}$ to $3.125 \mathrm{nM}$ with 2-fold dilution) were applied to flow over the chip surface, which was regenerated with $3 \mathrm{M} \mathrm{MgCl}_{2}$ after each cycle. The affinity was calculated using a 1:1 (Langmuir) binding fit model or two state reaction model with BIA evaluation software. Experiments were performed in triplicate, value=Mean \pm standard error.

\section{ELISA -based IL2-binding inhibition assay}

CD25 protein (10165-H08H, Sino Biological) was coated on high binding ELISA plates with $0.5 \mu \mathrm{g} / \mathrm{mL}$ at $4^{\circ} \mathrm{C}$ overnight. Plates were blocked with $3 \%$ skim milk powder in PBST (PBS containing $0.05 \%$ Tween-20) at $37^{\circ} \mathrm{C}$ for 1 hour. The mixture of IL2-biotin $(0.03 \mu \mathrm{g} / \mathrm{ml})$ and serially diluted CD25 antibodies were added to the blocked ELISA plate and incubated at $37^{\circ} \mathrm{C}$ for 1 hour. After washing, the biotinylated IL2 binding to coated CD25 was detected by HRP-conjugated Streptomycin. Experiments were performed in duplicate, value=Mean \pm SEM.

\section{In vitro IL-2 signaling by STAT5 phosphorylation assay}


PBMCs were co-cultured with $10 \mu \mathrm{g} / \mathrm{mL}$ CD25 antibody in a $96-U$ bottom plate for 30 minutes, then $1 \mathrm{U} / \mathrm{mL}$ IL2 was added and cultured for 10 minutes (working medium: $1640+10 \%$ FBS, containing $2 \mathrm{mM} \mathrm{L-}$ Glutamine). Cell suspension was prepared as follows. $200 \mu \mathrm{L}$ Foxp3 fixation/breaking membrane working solution was added to cell pellet in each well and incubated for $30-60$ minutes at $2-8^{\circ} \mathrm{C}$ or room temperature in the dark. After the sample was centrifuged at $400-600 \mathrm{~g}$ for 5 minutes at room temperature, the supernatant was discarded and plates were washed twice with $200 \mu \mathrm{L} /$ well $1 \mathrm{X}$ rupture solution and once with PBS at room temperature. Ice-cold Phosflow ${ }^{T M}$ Perm Buffer III was slowly added and then incubated on ice for 30 minutes. After washing two times by FACS buffer, cells were stained with fluorescent-labeled antibody at $4{ }^{\circ} \mathrm{C}$ for $30 \mathrm{~min}$ and then analyzed by NovoCyte 2060R flow cytometry. Experiments were performed in duplicate, value=Mean \pm SEM.

\section{Epitope binning}

Epitope binning of the antibodies was performed on a ForteBio Octet Red96 system (Pall Forte BioCorporation, Menlo Park, CA) using in-tandem format binning assay. CD25-biotin was loaded onto SA sensors (18-5019, fortebio). The sensors were then exposed to the first antibody with $50 \mu \mathrm{g} / \mathrm{mL}$ or PBST for $300 \mathrm{~s}$, then to the second antibody with $50 \mu \mathrm{g} / \mathrm{mL}$ for $300 \mathrm{~s}$. Data was processed using ForteBio's Data Analysis Software 9.0.

\section{Syngeneic mouse models}

All animal works were carried out in compliance with ARRIVE guidelines (https://arriveguidelines.org). These experiments were carried out at Beijing Biocytogen Co. Ltd.

For early phase of tumor development, mice were randomized into three groups, with 8 mice per group based on their body weight at day -1 (the day before tumor inoculation). Then BA9 and BT942 were dosed at $10 \mathrm{mg} / \mathrm{kg}$ intraperitoneally twice a week with vehicle group as the control. $5 \times 10^{5}$ MC38 cells in PBS were inoculated subcutaneously in the flank of mice at the next day (day 0 ). On day 16 , three mice in each group were sacrificed to test the proportion of $\mathrm{CD} 45^{+} \mathrm{T}, \mathrm{CD} 3^{+} \mathrm{T}, \mathrm{CD} 4^{+} \mathrm{T}, \mathrm{CD} 8^{+} \mathrm{T}, \mathrm{CD} 25^{+} \mathrm{Foxp} 3^{+}, \mathrm{Foxp}^{+}$ (Treg) cells in tumor by FACS. Animals were euthanized by $\mathrm{CO} 2$ asphyxiation when the mean tumor volume reached about $1300 \mathrm{~mm}^{3}$ (day 21).

For late phase of tumor development, B-hIL2RA humanized mice were implanted with $5 \times 10^{5}$ cells MC38 cells subcutaneously in the flank (day 0$)$. Mice were distributed into three groups $(n=8)$ with group mean starting volumes of 50 to $60 \mathrm{~mm}^{3}$ (day 5). Then BA9 and BT942 were also dosed at $10 \mathrm{mg} / \mathrm{kg}$ intraperitoneally twice a week with vehicle group as the control. Animals were euthanized by $\mathrm{CO} 2$ asphyxiation when the mean tumor volume reached about $2000 \mathrm{~mm}^{3}$ (day 19). On day 19, four mice in each group were sacrificed to test the proportion of $\mathrm{CD} 45^{+} \mathrm{T}, \mathrm{CD} 3^{+} \mathrm{T}, \mathrm{CD} 4^{+} \mathrm{T}, \mathrm{CD} 8^{+} \mathrm{T}, \mathrm{CD} 25^{+} \mathrm{Foxp} 3^{+}, \mathrm{Foxp}^{+}$ (Treg) cells in tumor and peripheral blood by FACS. 
For the synergistic effect of BT942 and anti-mouse PD1 antibody at late phase of tumor development, BhIL2RA humanized mice were implanted with $5 \times 10^{5}$ MC38 cells subcutaneously in the flank (day 0 ). Mice were distributed into four groups with 5 mice per group and treated with BT942, anti-mouse PD1 (BioXCell), their combination or vehicle when mean tumor volumes reached 50 to $60 \mathrm{~mm}^{3}$ at day 4 . Animals were euthanized by $\mathrm{CO} 2$ asphyxiation when mean tumor volume reached about $2000 \mathrm{~mm}^{3}$ (day 19).

Tumor size was measured twice a week by caliper. Tumor volumes were calculated as volume $=\left(w^{2} \times \mid\right) / 2$ where $w$ is the tumor width and $I$ is the tumor length in millimeters. For more information please see Methods in Supplementary Information.

\section{Pharmacodynamic and pharmacokinetics experiments}

All animal care and experimental procedures were complied with relevant ethical regulations regarding animal research. Pharmacokinetics and pharmacodynamic study protocols in monkeys were approved by Institutional Animal Care and Use Committee(IACUC) and the Approval Number was UPP-IACUC-202000000. The BT942 antibody was administered intravenously to cynomolgus monkeys $(N=2,2$ males, body weight $3 \sim 5 \mathrm{~kg}$ ) at a dose of $10 \mathrm{mg} / \mathrm{kg}$. Peripheral bloods were collected at predose and $1 \mathrm{~min}, 30$ min, 1h, 3h, 6h, 24h, 48h, 96h, 168h, 240h, 336h, 504h post-dose for PK study. ELISA (enzyme-linked immunosorbent assay) was used to determine the concentration of BT942 in serum. In this method, CD25 protein was used as the capture reagent, and goat anti-human IgG, monkey ads-HRP was detecting agent. Results are shown as mean \pm SEM. The main PK kinetic parameters were calculated using Phoenix WinNonlin.

Peripheral bloods were collected at pre-dose and $1 \mathrm{~min}, 3 \mathrm{~h}, 6 \mathrm{~h}, 24 \mathrm{~h}, 48 \mathrm{~h}, 72 \mathrm{~h}, 168 \mathrm{~h}, 336 \mathrm{~h}$ post-dose to determine $\mathrm{CD}^{+}{ }^{+} \mathrm{CD} 25^{+} \mathrm{FoxP}^{+}$percentage in $\mathrm{CD} 4+\mathrm{T}$ cells with flow cytometry (CytomicsTM FC500).

\section{Statistical analysis}

Statistical analysis was performed using SPSS 21.0. The tumor volumes were compared between treatment and control groups and the differences were assessed for significance using One-way ANOVA. Inter-group differences for percentages of different cell populations in tumor were assessed using Dunnett-t test (two-tailed). Data were presented as Mean \pm SEM. The threshold of significance was set at $\mathrm{p}<0.05$.

\section{Data availability}

The variable region sequences of BT942 MAb have been deposited in GenBank with the accession codes MW251337 for heavy chain and MW251338 for light chain. The variable region sequences of BA9 MAb have been deposited in GenBank with the accession codes MW251339 for heavy chain and MW251340 for light chain. 


\section{Results}

\section{Phage display screening identifies CD25-specific antibody candidates BT942 and BA9}

To identify potential CD25 targeting antibodies immunized human antibody transgenic mice were used in conjunction with phage display. Human antibody transgenic mice were immunized with CD25 protein (see Methods). Titers of antibodies in the mice serum were tested by ELISA. Three days after the last immunization, the spleen was harvested from each mouse and used in the construction of the phage libraries. Phage library developed as detailed previously (See Methods). For this plates coated with CD25 or streptavidin-magnetic beads binding biotin-CD25 were used to capture interest phages. Enriched phages were used to infect $E$. coli TG1 for expressing single-chain variable fragments (scFvs) and the binding and blocking activity were tested by ELISA. Positive clones obtained were sequenced and converted to IgG1 for in vitro evaluation. These analyses obtained two candidates BT942 and BA9 (Supplementary Figure S1).

\section{Monoclonal antibodies BA9 and BT942 displayed specific binding activity to CD25}

To assess the binding activity of antibody candidates BT942 and BA9 to CD25 enzyme-linked immunosorbent assay (ELISA), flow cytometry (FACS) and surface plasmon resonance (SPR) analysis were used.

ELISA was used to detect the binding of BA9 and BT942 to recombinant CD25 (see Methods). As shown in Figure 1a, BT942 and BA9 bound recombinant CD25 protein specifically (BA9 EC50 $=1.70 \mathrm{ng} / \mathrm{mL}$, BT942 EC50 $=2.64 \mathrm{ng} / \mathrm{mL}$ ).

Since it is difficult to obtain Treg cells from human tumors, we used Human diffuse tissue lymphoma cell line SU-DHL-1 and CD25 gene transfected HEK293T cells to perform in vitro cell-based evaluation using FACS. Binding analysis of BA9 and BT942 revealed that both antibody candidates could specifically bind to SU-DHL-1 cells with EC50 of $0.35 \mu \mathrm{g} / \mathrm{mL}$ and $1.20 \mu \mathrm{g} / \mathrm{mL}$, respectively (Figure 1b). Similar results were seen using HEK293T-CD25 cell line with EC50 as $1.71 \mu \mathrm{g} / \mathrm{mL}$ and $2.21 \mu \mathrm{g} / \mathrm{mL}$, respectively (Figure 1c).

Binding kinetics of BT942 and BA9 to CD25 were measured by SPR using a Biacore 8K. The equilibrium constants (KD) of BA9 and BT942 with CD25 were $1.29 \pm 0.03 \mathrm{nM}$ and $8.84 \pm 1.16 \mathrm{nM}$, respectively (Figure 1d, e). BA9 and BT942 also showed they can react with cynomolgus CD25 with a KD of $1.70 \pm 0.04 \mathrm{nM}$ and $4.33 \pm 1.83 \mathrm{nM}$, respectively (Figure $1 \mathbf{f}, \mathbf{g}$ ). However, no reaction with mouse CD25 was observed (Supplementary Figure S2). Notably, BA9 had higher binding affinity than BT942 in all the above in vitro data.

\section{BA9 and BT942 both do not prevent IL2 binding to CD25 and the activation of downstream signaling pathway but bind distinct epitopes on CD25}

As CD25 is transiently expressed on a small population of activated Teff cells, IL-2 can stimulate the effector T cells through the IL-2 receptor complex to facilitate tumor suppression. Therefore, we examined 
if the binding of BA9 and BT942 to CD25 alters IL-2 signaling, by analyzing the phosphorylation of STAT5 in PBMCs by flow cytometry (see Methods).

The data in Figure 2a show that BA9 and BT942 do not block the interaction of IL-2 with CD25. Furthermore, BA9 and BT942 do not block the activation of IL-2 on the IL-2R signaling pathway as assessed through monitoring phosphorylated STAT5 percentage in PBMC by FACS (Figure 2b).

Given that BA9 and BT942 both do not prevent IL2 binding to CD25, we measured the potential competitive binding of BA9 and BT942 to CD25 using an Octet 96 based epitope binding assay. For this recombinant CD25 protein was first biotinylated and immobilized on a streptavidin biosensor and then saturated with BA9 or BT942 (see Materials and Methods). Addition of BT942 to BA9 saturated probe or BA9 to BT942 saturated probe showed some partial complementary binding (Figure 2c, d), indicating BA9 and BT942 bind to similar but distinct epitopes of CD25.

\section{BA9 and BT942 demonstrated antibody-dependent cell-mediated cytotoxicity in vitro}

The antibody-dependent cell-mediated cytotoxicity (ADCC) is an important biological function attributed to the mechanism of action of Treg-deleting CD25 antibodies. The ADCC activity of BA9 and BT942 against SU-DHL-1 or HEK293T-CD25 were characterized using a reporter bioassay (Promega, G7940) (see Methods). BA9 and BT942 showed IC50 towards SU-DHL-1 as $24.69 \mathrm{ng} / \mathrm{mL}, 37.17 \mathrm{ng} / \mathrm{mL}$, and IC50 towards HEK293T-CD25 as $115.90 \mathrm{ng} / \mathrm{mL}, 95.10 \mathrm{ng} / \mathrm{mL}$, respectively (Figure 3a, b). Furthermore, BA9 and BT942 showed IC50 towards SU-DHL-1 as $5.57 \mathrm{ng} / \mathrm{mL}$ and $17.25 \mathrm{ng} / \mathrm{mL}$ when evaluated by antibodydependent cell-mediated cytotoxicity (Figure 3c).

\section{BA9 and BT942 demonstrated significant tumor suppression in both early phase and late phase of tumor establishment}

The effect of BA9 and BT942 on tumor suppression at early phase of tumor development was investigated in MC38 Model in B-hIL2RA humanized mice. 8 mice for each antibody were administered intraperitoneally at $10 \mathrm{mg} / \mathrm{kg}$ on day -1 (the day before tumor inoculation) with vehicle group as control. Both BA9 and BT942 significantly reduced tumor growth; the Tumor Growth inhibition (TGI) was 60.6\% and $66.6 \%$ (Figure $4 a$ ), respectively.

To examine the effect of BA9 and BT942 on late phase tumor development 8 mice per group were administered at $10 \mathrm{mg} / \mathrm{kg}$ on day 5 when group mean tumor volumes had grown to $50-60 \mathrm{~mm}^{3}$. Like early phase results the antibodies demonstrated significantly reduced tumor growth; the TGI for BA9 and BT942 was $48.7 \%$ and $74.7 \%$, respectively (Figure 5a). Overall, BT942 showed a significant tumor suppression effect whether administered in the early or late phase of tumor establishment and had a significant advantage over BA9 in the late phase.

The immune cell population in tumors and peripheral blood cells was also monitored in the same experiments. In the late phase treatment experiment, BA9 and BT942 not only significantly reduced the 
proportion of hCD $25^{+} \mathrm{Foxp} 3^{+}$cells and Treg cells (Figure $5 \mathrm{~b}, \mathrm{c}$ ), but also increased the proportion of $\mathrm{CD}^{+} \mathrm{T}, \mathrm{CD} 45^{+}, \mathrm{CD}^{+} \mathrm{T}$, and $\mathrm{CD} 4^{+} \mathrm{T}$ cells in tumor cells (Figure 5d, Supplementary Fig. S4). In the early phase treatment experiment, BA9 and BT942 also reduced the proportion of $\mathrm{hCD} 25^{+} \mathrm{mFoxp} 3^{+}$cells and Treg cells in the tumor cells (Figure $4 b, c)$. Interestingly, there were more residual Treg cells ( $p$-value $=0.0114,0.0210$ ) after BT942 treatment than BA9, in both early and late phase treatment (Figure 4c, 5c). BT942 treatment also resulted in a significant bigger increase in $\mathrm{CD}^{+} \mathrm{T}$ percentage at early phase treatment experiment when compared to BA9 treatment $(p$-value $=0.0194)($ Figure $4 d)$. This difference was also seen in $C D 45^{+} T$ ( $p$-value $\left.=0.0136,0.0189\right), C D 3^{+} T$ ( $p$-value $\left.=0.0074,0.0421\right)$ and $C D 4^{+} T(p-$ value $=0.0148,0.0301$ ) proportions in both early and late phase treatment (Supplementary Fig. S4).

In the late phase treatment experiment, BA9 significantly reduced the proportion of $\mathrm{hCD} 25^{+} \mathrm{Foxp} 3^{+}$cells and Treg cells in peripheral blood cells, but BT942 only had a slight effect (Supplementary Fig. S5). Unlike in tumor cells, there was no significant changes of $C D 45^{+} T, C D 4^{+} T, C D 8^{+} T$ proportion in peripheral blood in the late phase treatment experiment for both BA9 and BT942 (Supplementary Fig. S5).

\section{BT942 appears more effective in vivo than BA9}

Although BT942 had weaker binding activity than BA9 to both CD25 and CD25-expressing cells, it had a significant advantage over BA9 in terms of in vivo efficacy, especially in the late phase. In addition, there is a higher residue of Treg and greater increase of $\mathrm{CD} 45^{+} \mathrm{T}, \mathrm{CD} 8^{+} \mathrm{T}$ and $\mathrm{CD} 4^{+} \mathrm{T}$ cells in the tumor in response to BT942 than BA9 in both early and late phase treatments. To understand the difference in performance between BT942 than BA9, we analyzed aspects of antibody action. Compared the ADCC activity of BT942 and BA9 against in vitro activated CD8 $8^{+}$T cells or SU-DHL-1 cells (SU-DHL-1 cells were used to instead tumor Tregs). BT942 showed weaker ADCC activity than BA9 on both CD8 ${ }^{+} \mathrm{T}$ and SUDHL-1 cells weather evaluated by antibody-dependent cell-mediated cytotoxicity (Figure 3c, d) or by an ADCC reporter bioassay (Figure 3a, Supplementary Figure S3). It is possible that because of this lower activity, BT942 has differential effects on high expression Treg and low expression Teff cells, and that this contributes to making it a successful anti-CD25 candidate.

\section{BT942 synergizes with anti-PD1 to eradicate established tumors}

Treg's inhibition of Teff cells in tumor is one of the reasons for the low response of PD1/PDL1 inhibitors. PD1 inhibitors can relieve the inhibition of $\mathrm{CD} 8^{+} T$ cells and promote the proliferation and activation of Teff cells in the tumor; while anti-CD25 antibody can delete the Treg and further increase the ratio of CD $8^{+}$ T/Treg in the tumor. We examined combining BT942 and anti-Mouse PD1(Bio X cell, BE0146) to see if they had a synergistic effect in MC38 Model in B-hIL2RA humanized mice. MC38 cells $\left(5 \times 10^{5}\right.$ cells) were injected subcutaneously into B-hIL2RA mice. Mice were treated with BT942, anti-mouse PD1, or their combination with vehicle group as control when tumors reached $50-60 \mathrm{~mm}^{3}$. The inhibitory rate of BT942 on the tumor is $57.9 \%$, the inhibitory rate of BT942 and PD1 antibody on the tumor is $74.5 \%$, the combined use significantly improved the effect of the single mAb (Figure 6, Supplementary Table S2) 
MC38 cells $\left(5 \times 10^{5}\right.$ cells) were injected s.c. into B-hIL2RA mice. Antibody treatments were started when tumors reached $50-60 \mathrm{~mm}^{3}$. Mice were treated with BT942, anti-mouse PD1 (BioXCell), their combination or vehicle when mean tumor volumes reached 50 to $60 \mathrm{~mm}^{3}(n=5)$. Tumor size was measured twice a week by caliper. Data were presented as Mean \pm SEM.

\section{Pharmacodynamic and pharmacokinetic evaluation of BT942 in cynomolgus monkeys}

As BT942 showed a significant efficacy in vivo we evaluated the pharmacodynamic and pharmacokinetic (PK) characteristics of this novel anti-CD25 antibody using healthy cynomolgus monkeys. For these experiments 2 animals were administered BT942 intravenously at doses of $10 \mathrm{mg} / \mathrm{kg}$ (see Methods). ELISA (enzyme-linked immunosorbent assay) was used to determine the concentration of BT942 in serum. Following a single-dose injection, BT942 showed a bi-exponential serum concentration-time profile with a short distribution phase followed by a long elimination phase, with a terminal half-life (t1/2, $\lambda z$ ) of $206.97 \pm 19.03$ hours and $A U_{(0-t)}$ of $32036.89 \pm 1234.97 \mathrm{~h} * \mu \mathrm{g} / \mathrm{mL}$ (Figure 7a; Supplementary Table S3). Interestingly, the pharmacodynamic tests showed that the percentage of $\mathrm{CD} 4^{+} \mathrm{CD} 25^{+} \mathrm{Foxp} 3^{+}$cells in peripheral blood decreased significantly a few hours after administration, and it was still very low until 336 hours (Figure 7b). This indicated that the effect of BT942 was durable.

\section{Discussion}

Tregs protect cancer cells from immune attack. Tregs express CD25 on their surface and can be killed by antibodies and immunoconjugates targeting CD25. These antibodies have not been effective in controlling tumor growth of patients, probably because they also kill cytotoxic $\mathrm{CD} 8^{+} \mathrm{T}$ cells expressing CD25 that are needed for antitumor activity. Here we describe two anti-CD25 monoclonal antibodies, BT942 and BA9, that were obtained through immunizing human antibody transgenic mice with recombinant CD25 protein followed by phage display for library construction and potential hits screening with CD25 protein. BT942 has a significant efficacy on both early and late stage MC38 colon cancer models, whether used alone or in combination with anti-PD1. The previously examined anti-CD25 monoclonal antibodies are either effective only in the early stages of tumors ${ }^{20}$, or only have a significant efficacy in combination with anti-PD1 27.

BT942 has weaker binding activity to CD25 and weaker ADCC activity against CD25- expressing cells compared with BA9. Nevertheless, BT942 had a stronger tumor growth inhibitory ability and led to a higher $\mathrm{CD} 45^{+} \mathrm{T}, \mathrm{CD} 8^{+} \mathrm{T}$ and $\mathrm{CD} 4^{+} \mathrm{T}$ increase than BA9 in MC38 model. CD25 is also transiently expressed on activated Teff cells although at lower percentage of the population and a lower expression level than Treg cells. We hypothesize that an anti-CD25 antibody such as BT942 exerts the stronger tumor killing power as it can kill Treg cells while interfering with $\mathrm{CD} 8^{+} \mathrm{T}$ cells to a minimal degree (Supplementary Figure S6). The moderate activity of the Fab region is also very important for the successful development of anti-CD25. As BA9 and BT942 appear to recognize different epitopes, the epitope of BT942 may also contribute its stronger efficacy in mice. 
In addition, tumor growth inhibitory of BT942 demonstrated synergy in combination with PD1 antibody using MC38 model and is higher than that of BT942 or anti-mouse PD1 alone. In terms of toxicity, the removal of Treg cells could trigger the excessive immune responses to microbial antigens, which will lead to the $T$ cells hyper-reaction to intestinal commensal bacteria, causing inflammatory bowel disease (IBD), and other diseases ${ }^{28}$. For BT942, there was no significant reduction in animal weight and clinical observation did not find any abnormalities in mice efficacy study or in monkey PD\PK study.

There haven't been CD25 antibodies demonstrated efficacy against cancer in clinic till now. BT942 appears to be an excellent candidate for the generation of a human reagent that may be used in clinic for the immunotherapy of cancer.

\section{Declarations}

\section{Acknowledgments}

We thank all colleagues from Shandong Boan biotechnology and Shandong Luye Pharmaceutical (Yantai) for their support during the study. We are grateful to Shi-qi An for her help to revise the manuscript.

\section{Author Contributions}

C.D. initiated the project and guide the experiments. D.S. designed the experiments and wrote the manuscript with XL's help. X.L. conducted the ADCC experiments and data analysis. C.C.D. did the antibody screening based phage display. C.S. and X.S. performed the PK studies. Z.N. prepared the transgenic mice. Q.W. conducted antigen immunization and designed the animal studies. J.H. and M.Z. performed the ELISA experiments. H.L. constructed and sequenced the antibodies. H.X. and P.X. performed the antibody purification. H.Z. performed the FACS experiments. Y.L. and G.L. performed cell culture for antibody expression. All authors reviewed the manuscript.

\section{Funding}

Boan biotechnology sponsored the studies.

\section{Competing interests}

The authors declare no competing interests.

\section{Additional information}

Correspondence and requests for materials should be addressed to C.D. or D.S.

\section{References}


1. Jonuleit, H. \& Schmitt, E. The regulatory T cell family: distinct subsets and their interrelations. $J$ Immuno/ 171, 6323-6327, doi:10.4049/jimmunol.171.12.6323 (2003).

2. Whiteside, T. L. Regulatory T cell subsets in human cancer: are they regulating for or against tumor progression? Cancer Immunol Immunother 63, 67-72, doi:10.1007/s00262-013-1490-y (2014).

3. Frydrychowicz, M., Boruczkowski, M., Kolecka-Bednarczyk, A. \& Dworacki, G. The Dual Role of Treg in Cancer. Scand J Immuno/ 86, 436-443, doi:10.1111/sji.12615 (2017).

4. Sakaguchi, S., Yamaguchi, T., Nomura, T. \& Ono, M. Regulatory T cells and immune tolerance. Cell 133, 775-787, doi:10.1016/j.cell.2008.05.009 (2008).

5. Sakaguchi, S., Sakaguchi, N., Asano, M., Itoh, M. \& Toda, M. Immunologic self-tolerance maintained by activated T cells expressing IL-2 receptor alpha-chains (CD25). Breakdown of a single mechanism of self-tolerance causes various autoimmune diseases. $J$ Immuno/ 155, 1151-1164 (1995).

6. Sakaguchi, S. The origin of FOXP3-expressing CD4+ regulatory T cells: thymus or periphery. J Clin Invest 112, 1310-1312, doi:10.1172/JCI20274 (2003).

7. Woo, E. Y. et al. Regulatory CD4(+)CD25(+) T cells in tumors from patients with early-stage non-small cell lung cancer and late-stage ovarian cancer. Cancer Res 61, 4766-4772 (2001).

8. Liyanage, U. K. et al. Prevalence of regulatory T cells is increased in peripheral blood and tumor microenvironment of patients with pancreas or breast adenocarcinoma. J Immuno/ 169, 2756-2761, doi:10.4049/jimmunol.169.5.2756 (2002).

9. Wolf, A. M. et al. Increase of regulatory T cells in the peripheral blood of cancer patients. Clin Cancer Res 9, 606-612 (2003).

10. Sasada, T., Kimura, M., Yoshida, Y., Kanai, M. \& Takabayashi, A. CD4+CD25+ regulatory T cells in patients with gastrointestinal malignancies: possible involvement of regulatory $T$ cells in disease progression. Cancer 98, 1089-1099, doi:10.1002/cncr.11618 (2003).

11. Woo, E. Y. et al. Cutting edge: Regulatory T cells from lung cancer patients directly inhibit autologous T cell proliferation. J Immuno/ 168, 4272-4276, doi:10.4049/jimmunol.168.9.4272 (2002).

12. Shang, B., Liu, Y. \& Jiang, S. J. Prognostic value of tumor-infiltrating FoxP3+ regulatory T cells in cancers: a systematic review and meta-analysis. Sci Rep 5, 15179, doi:10.1038/srep15179 (2015).

13. Bates, G. J. et al. Quantification of regulatory T cells enables the identification of high-risk breast cancer patients and those at risk of late relapse. J Clin Oncol 24, 5373-5380, doi: 10.1200/JCO.2006.05.9584 (2006).

14. Curiel, T. J. et al. Specific recruitment of regulatory T cells in ovarian carcinoma fosters immune privilege and predicts reduced survival. Nat Med 10, 942-949, doi:10.1038/nm1093 (2004).

15. Gao, Q. et al. Intratumoral balance of regulatory and cytotoxic T cells is associated with prognosis of hepatocellular carcinoma after resection. J Clin Oncol 25, 2586-2593, doi: 10.1200/JCO.2006.09.4565 (2007).

16. Petersen, R. P. et al. Tumor infiltrating Foxp3+ regulatory T-cells are associated with recurrence in pathologic stage I NSCLC patients. Cancer 107, 2866-2872, doi:10.1002/cncr.22282 (2006). 
17. Perrone, G. et al. Intratumoural FOXP3-positive regulatory T cells are associated with adverse prognosis in radically resected gastric cancer. Eur J Cancer 44, 1875-1882, doi:

10.1016/j.ejca.2008.05.017 (2008).

18. Shah, W. et al. A reversed CD4/CD8 ratio of tumor-infiltrating lymphocytes and a high percentage of CD4(+)FOXP3(+) regulatory $T$ cells are significantly associated with clinical outcome in squamous cell carcinoma of the cervix. Cell Mol Immuno/ 8, 59-66, doi: 10.1038/cmi.2010.56 (2011).

19. Elpek, K. G., Lacelle, C., Singh, N. P., Yolcu, E. S. \& Shirwan, H. CD4+CD25+ T regulatory cells dominate multiple immune evasion mechanisms in early but not late phases of tumor development in a B cell lymphoma model. J Immunol 178, 6840-6848, doi: 10.4049/jimmunol.178.11.6840 (2007).

20. Onizuka, S. et al. Tumor rejection by in vivo administration of anti-CD25 (interleukin-2 receptor alpha) monoclonal antibody. Cancer Res 59, 3128-3133 (1999).

21. Shimizu, J., Yamazaki, S. \& Sakaguchi, S. Induction of tumor immunity by removing CD25+CD4+ T cells: a common basis between tumor immunity and autoimmunity. $J$ Immunol 163, 5211-5218 (1999).

22. Smyth, M. J., Ngiow, S. F. \& Teng, M. W. Targeting regulatory T cells in tumor immunotherapy. Immunol Cell Bio/ 92, 473-474, doi: 10.1038/icb.2014.33 (2014).

23. Bulliard, Y. et al. OX40 engagement depletes intratumoral Tregs via activating FcgammaRs, leading to antitumor efficacy. Immuno/ Cell Bio/ 92, 475-480, doi: 10.1038/icb.2014.26 (2014).

24. Simpson, T. R. et al. Fc-dependent depletion of tumor-infiltrating regulatory $T$ cells co-defines the efficacy of anti-CTLA-4 therapy against melanoma. J Exp Med 210, 1695-1710, doi: 10.1084/jem.20130579 (2013).

25. Bulliard, Y. et al. Activating Fc gamma receptors contribute to the antitumor activities of immunoregulatory receptor-targeting antibodies. J Exp Med 210, 1685-1693, doi: 10.1084/jem.20130573 (2013).

26. Boyman, O. \& Sprent, J. The role of interleukin-2 during homeostasis and activation of the immune system. Nat Rev Immunol 12, 180-190, doi: 10.1038/nri3156 (2012).

27. Arce Vargas, F. et al. Fc-Optimized Anti-CD25 Depletes Tumor-Infiltrating Regulatory T Cells and Synergizes with PD-1 Blockade to Eradicate Established Tumors. Immunity 46, 577-586, doi: 10.1016/j.immuni.2017.03.013 (2017).

28. Belkaid, Y. \& Rouse, B. T. Natural regulatory T cells in infectious disease. Nat Immuno/ 6, 353-360, doi: 10.1038/ni1181 (2005).

29. Carlos F. Barbas III, Dennis R. Burton, Jamie K. Scott, Gregg J. Silverman. Phage Display: A laboratory manual. 1-376 (Cold Spring Harbor Laboratory Press, 2001).

\section{Figures}




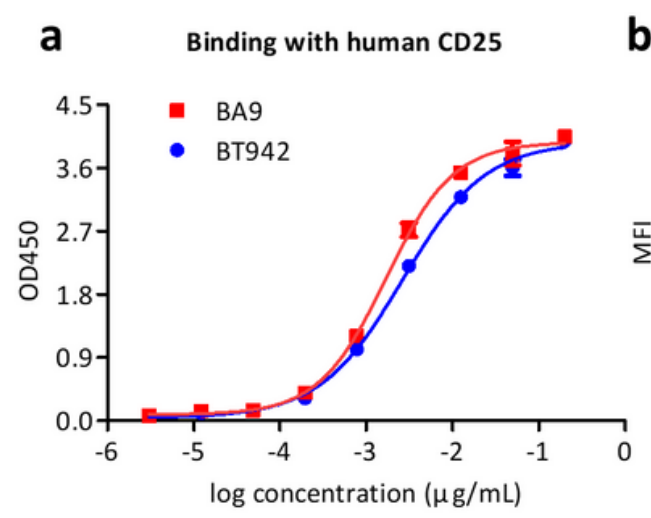

d

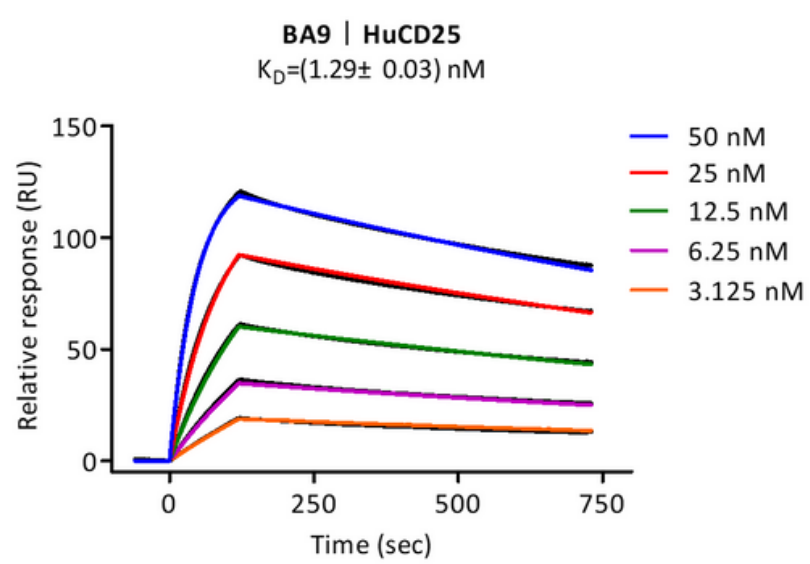

f

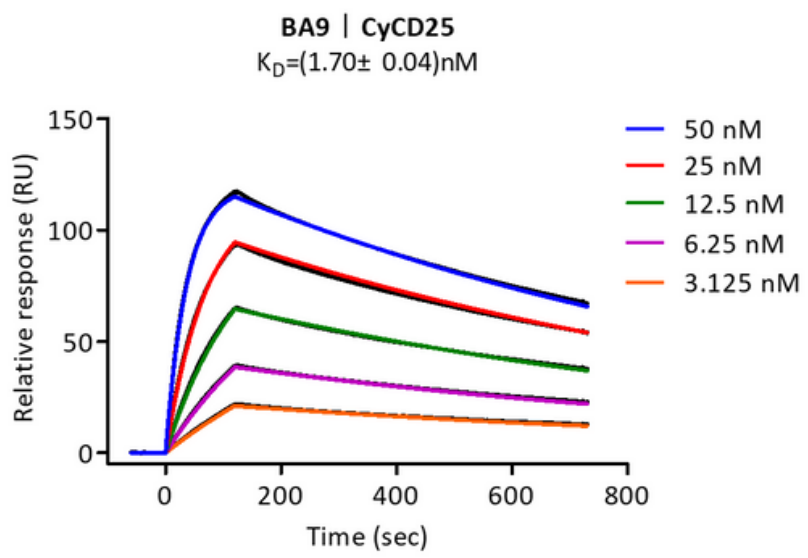

SU-DHL-1

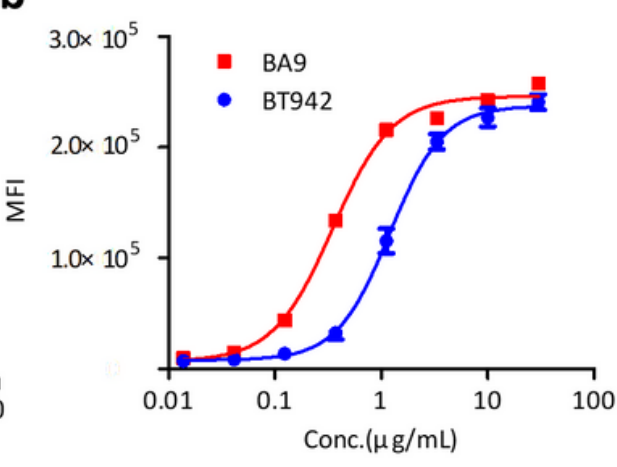

e
C

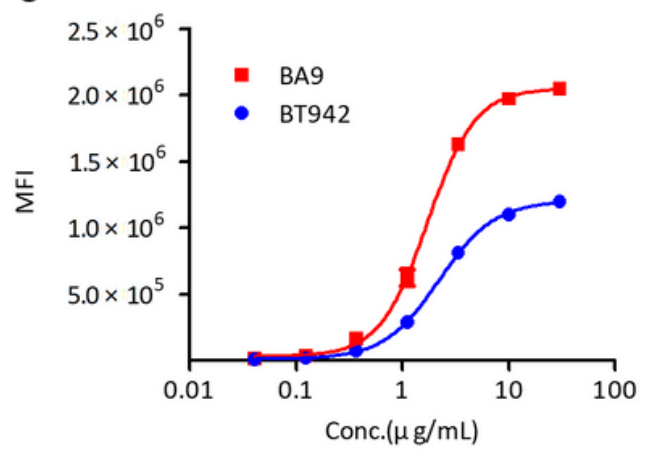

BT942 | HuCD25

$\mathrm{K}_{\mathrm{D}}=(8.84 \pm 1.16) \mathrm{nM}$

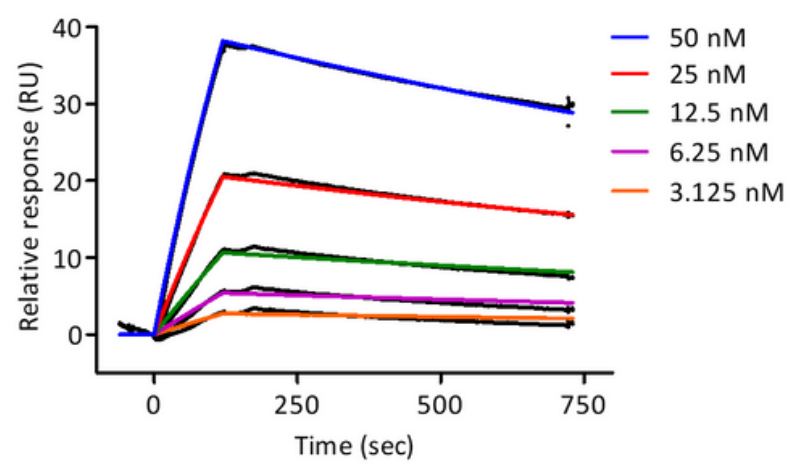

g

BT942 | CyCD25

$\mathrm{K}_{\mathrm{D}}=(4.33 \pm 1.83) \mathrm{nM}$

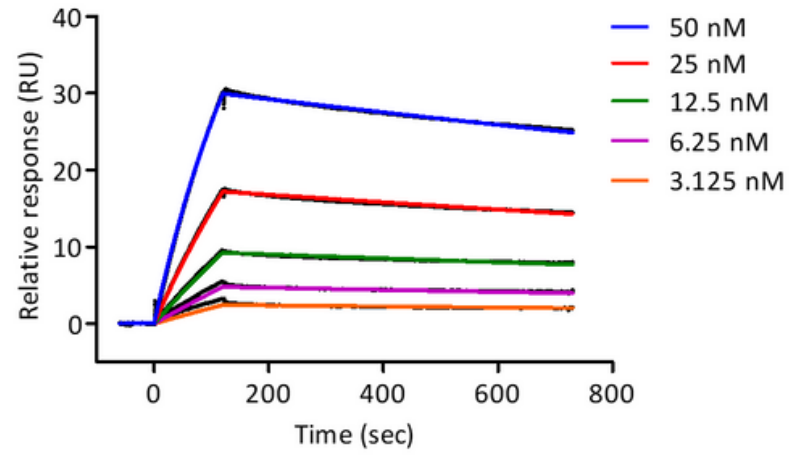

\section{Figure 1}

BA9 and BT942 specifically binding to human CD25 and cynomolgus CD25. a. BA9 and BT942 specifically bind to CD25 in ELISA. Data were presented as Mean \pm SEM.b. BA9 and BT942 specifically bind to SU-DHL-1 cells determined by flow cytometry. Data were presented as Mean \pm SEM. C. BA9 and BT942 specifically bind to HEK293T-CD25 cells determined by flow cytometry. Data were presented as Mean \pm SEM. d, e. Binding kinetics of BA9 (d) or BT942 (e) for HuCD25 were measured in a surface plasmon resonance (SPR) assay with BIAcore. Data of KD were presented as Mean \pm SD. $f$, g. Crossreactivity with cynomolgus CD25 by BA9 (f) and BT942 (g). Experiments were performed in triplicate. Data of KD were presented as Mean \pm SD. 
a

mAb blocking IL2 binding to CD25

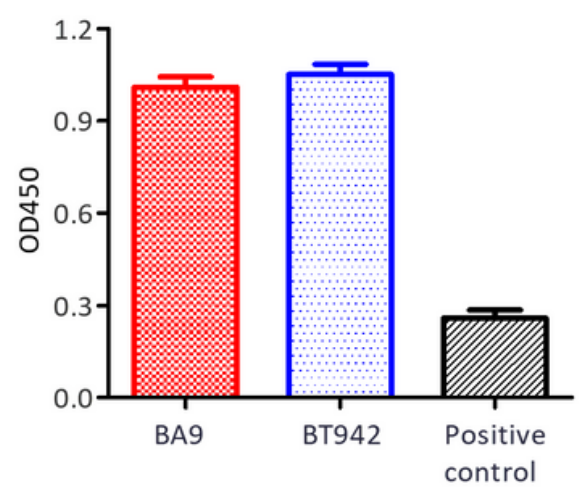

C

Competitive binding

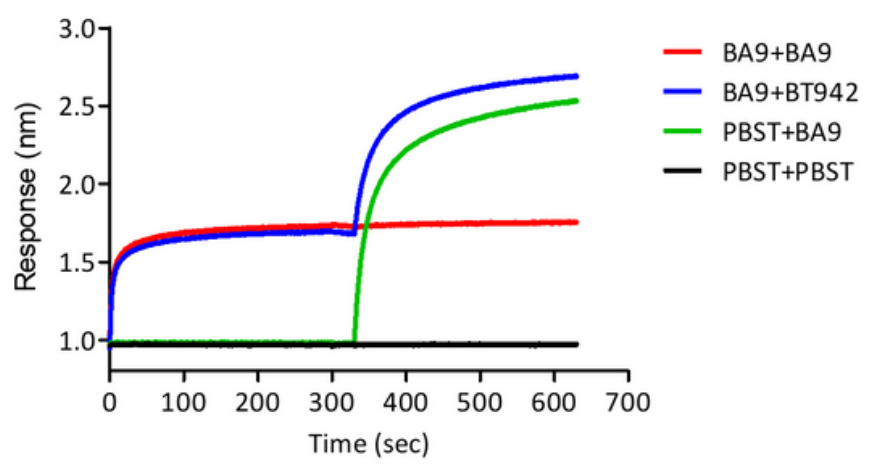

b mAb blocking IL2R Signal pathway activation by IL2

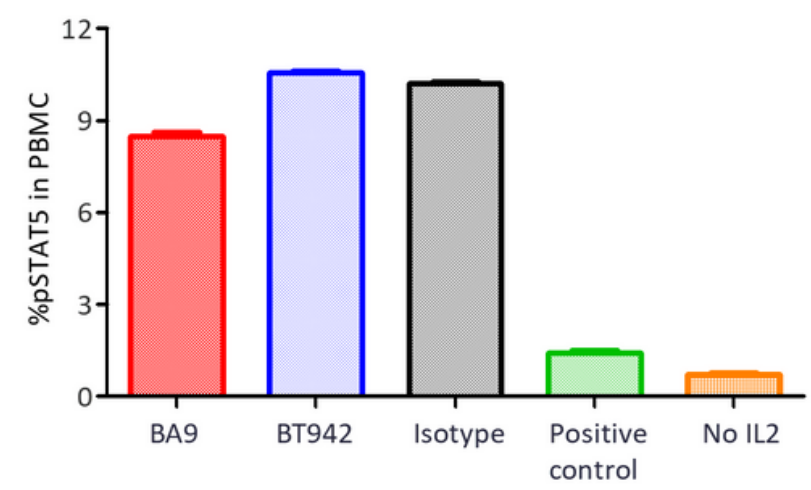

d

Competitive binding

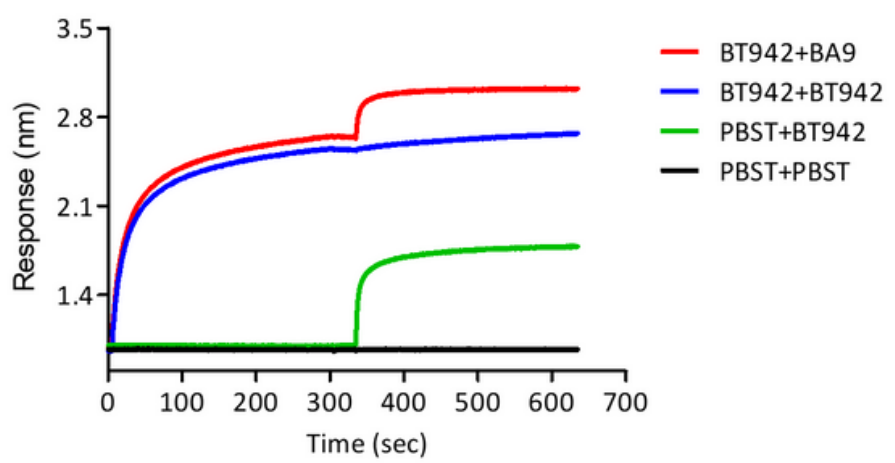

Figure 2

IL-2/IL-2 receptor blocking activity and Epitope binding characteristics of BA9 and BT942. a. BA9 and BT942 do not block IL-2 binding to CD25 in ELISA. BT865 was used as a positive control antibody that can block the binding of IL-2 and CD25. Data were presented as Mean \pm SEM. b. Characterization of antibodies compared to positive control and isotype antibody in respect to blocking IL-2 signaling in a STAT5 phosphorylation assay using human PBMCs. BA9 and BT942 not blocking IL-2 induced IL2R signal pathway activation by flow cytometry. CT805 that can block IL-2 induced IL2R signal pathway activation was used as a positive control. Data were presented as Mean \pm SEM. c, d. Epitope binding. Epitope binding of the antibodies was performed using in-tandem format binning assay. BT942 and BA9 partially competed each other, and the binding epitopes of the two antibodies are close but different on CD25. 
a

$A D C C$ by reporter bioassay

Effector cells: Jurkat

Target cells: SU-DHL-1

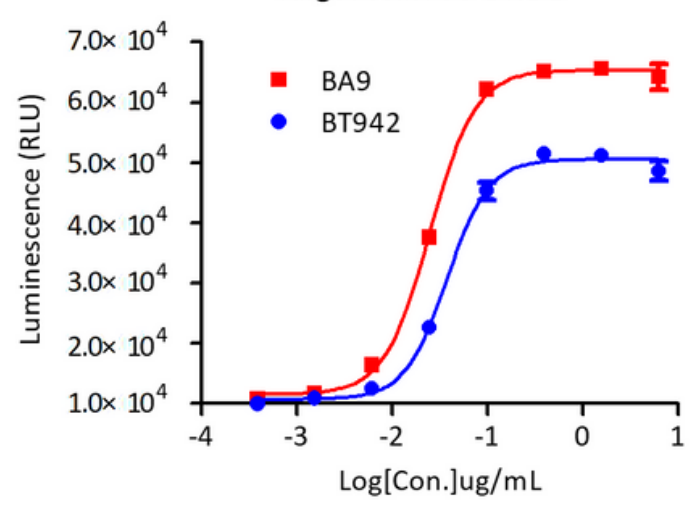

C

ADCC

Effector cells: PBMC

Target cells: SU-DHL-1

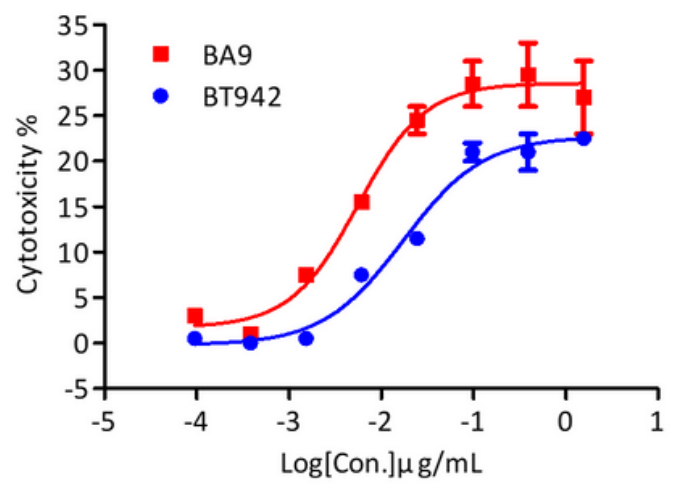

b

ADCC by reporter bioassay

Effector cells: Jurkat

Target cells: 293T-CD25

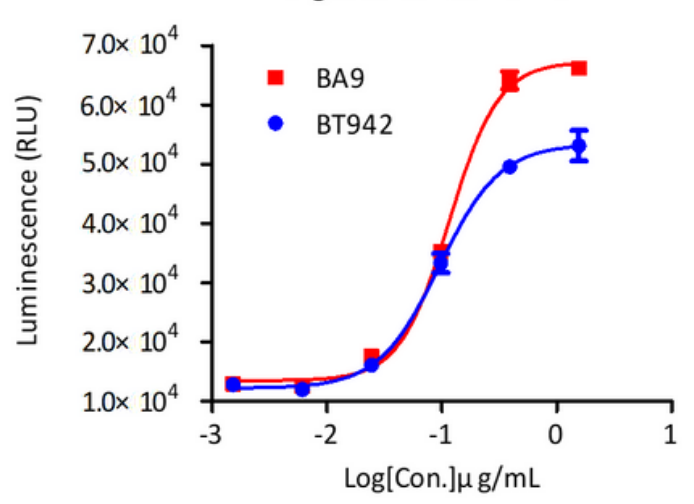

d

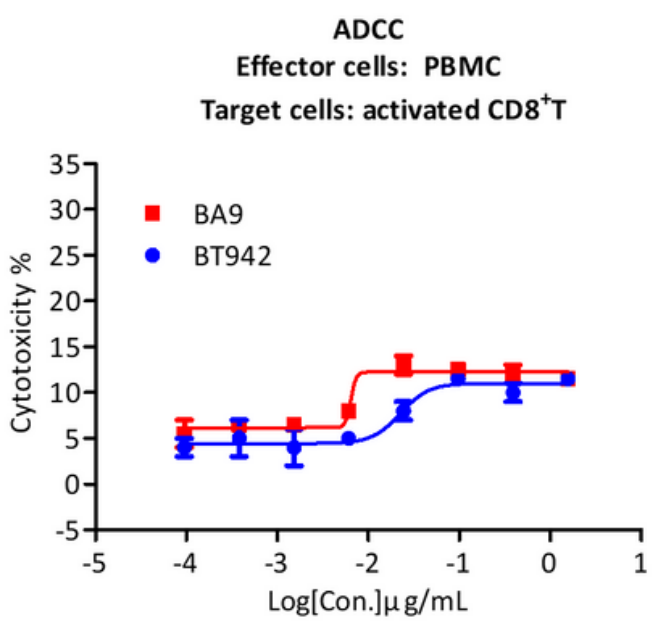

\section{Figure 3}

ADCC activity of BA9 and BT942. a, b. The target cells were SU-DHL-1(a) or 293T-CD25(b), the effector cells were Jurkat cells from Promega. BA9 can induced higher ADCC activity to both cell lines than BT942. Experiments were performed in duplicate. Data were presented as Mean \pm SEM. $c, d$. The target cells were SU-DHL-1(c) or activated CD8+T cells (d), the effector cells were PBMC. BA9 has higher ADCC activity than BT942. Experiments were performed in duplicate. Data were presented as Mean \pm SEM. 


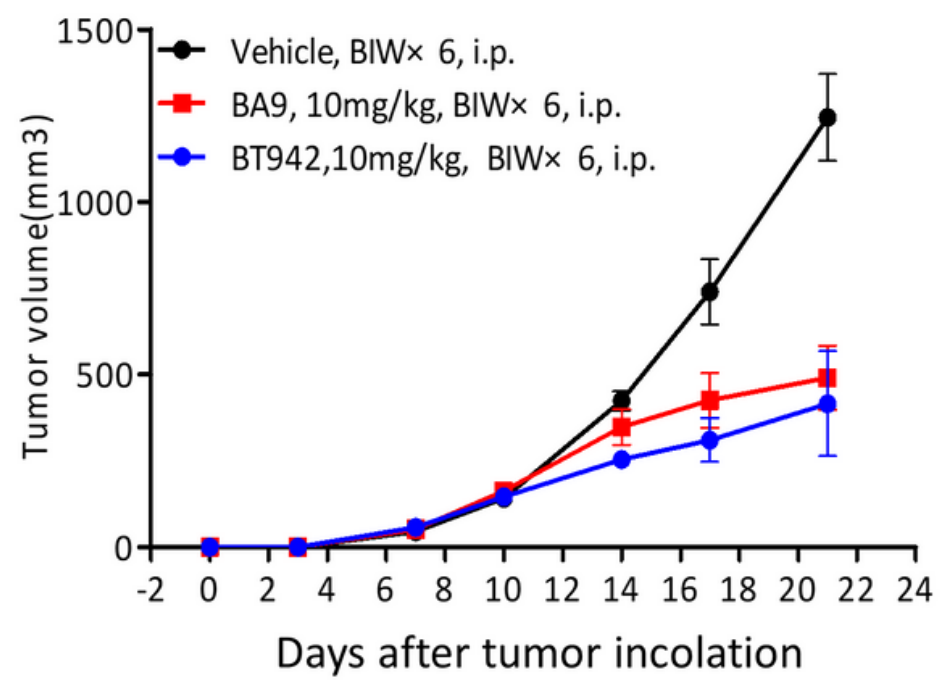

b

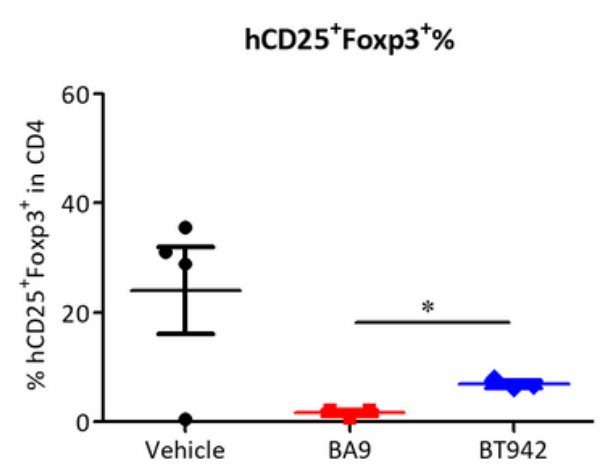

C

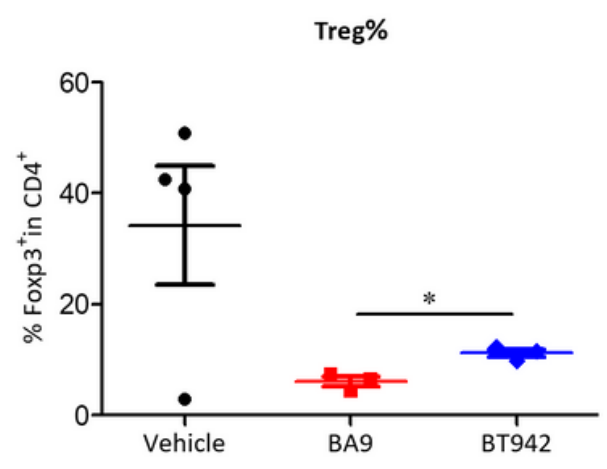

d

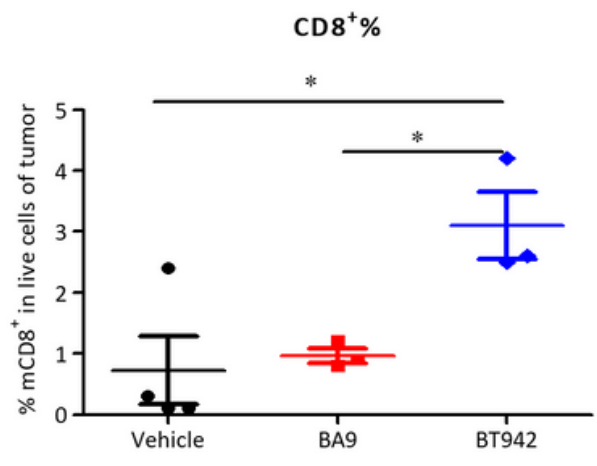

\section{Figure 4}

Antitumor effect of BA9 and BT942 in B-hIL2RA mice in MC38 tumor model for Early phase treatment. a. Early phase treatment: Mean tumor volume of MC38 implants in B-hIL2RA mice treated with control versus anti-CD25 ( $n=8 /$ group). Randomly, B-hIL2RA mice were grouped by weight and treated with antihCD25 antibody ( $10 \mathrm{mg} / \mathrm{kg}$, i.p., twice a week). MC38 cells ( $5 \times 105$ cells) were injected s.c. into mice in the next day (day 0). b, c, d. Quantification of hCD25+Foxp3+, Foxp3+ (Treg) and CD8+ T population percentage in MC38 tumors from early phase treatment. Compared with BA9, the residue of Tregs in tumors cells after BT942 treatment was more $(p=0.0114)$. $p$ values obtained by Dunnett-t test (twotailed). Data were presented as Mean \pm SEM. 


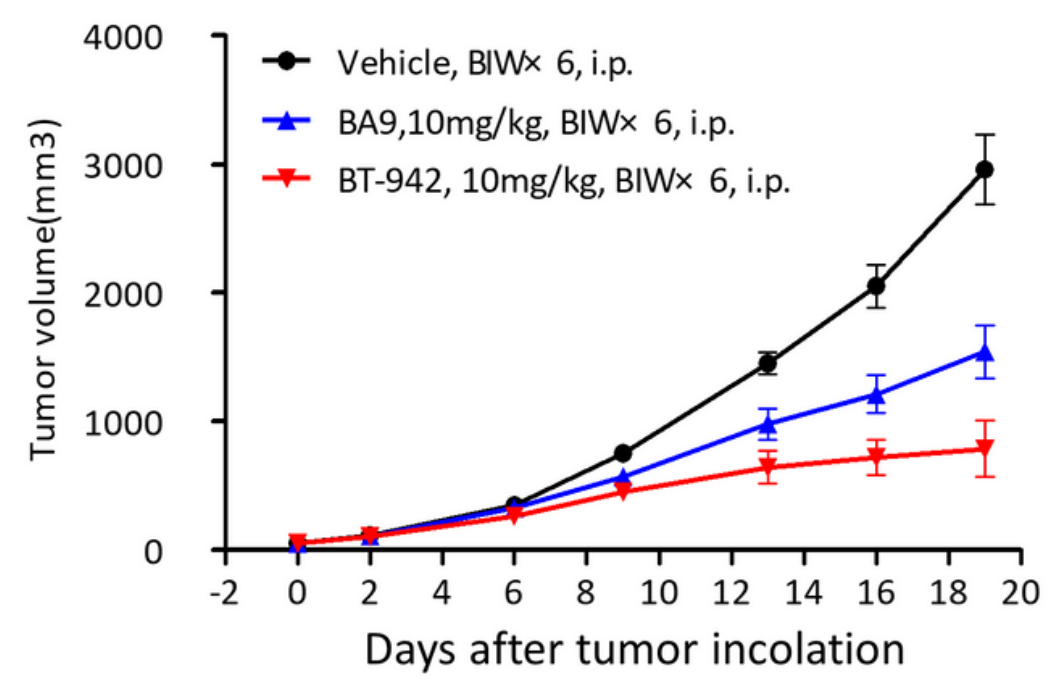

b

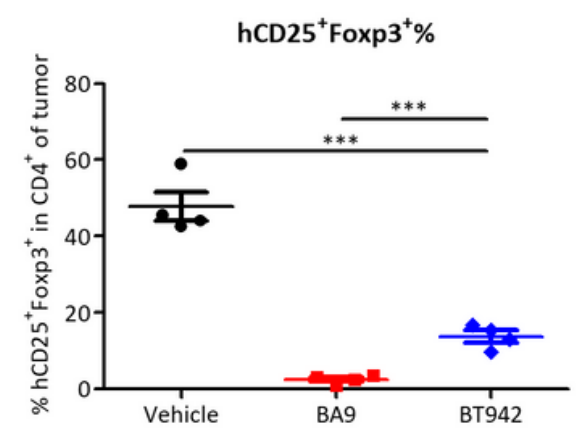

C

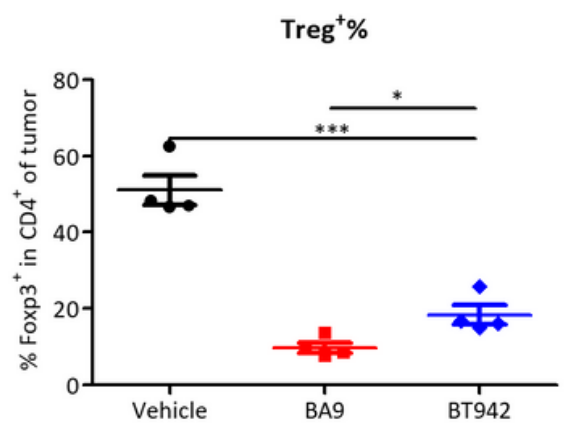

d

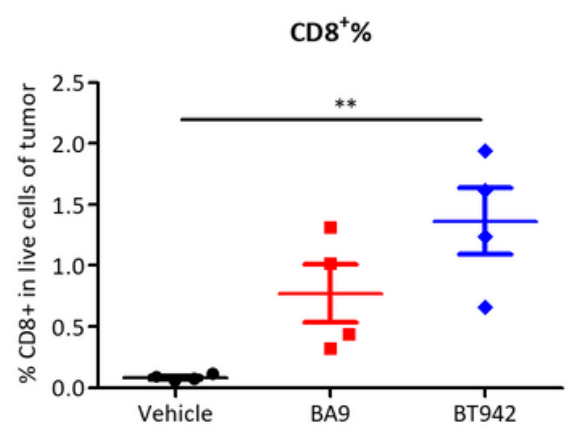

\section{Figure 5}

Antitumor effect of BA9 and BT942 in MC38 tumor model in B-hIL2RA mice for Late phase treatment. a. Late phase treatment: Mean tumor volume of MC38 implants in B-hIL2RA mice treated with control versus anti-CD25 ( $n=8)$. MC38 cells ( $5 \times 105$ cells) were injected subcutaneous into B-hIL2RA mice】day 0X. Antibody treatments $(10 \mathrm{mg} / \mathrm{kg}$, i.p., twice a week) were started when tumors had grown to $50-60 \mathrm{~mm} 3$ (day 5). b, c, d. Quantification of hCD25+Foxp3+, Foxp3+ (Treg) and CD8+ T population percentage in tumors cells from late phase treatment. $p$ values obtained by Dunnett-t test (two-tailed). Compared with BA9, the residue of Tregs in tumors cells after BT942 treatment was more $(p=0.0210)$. Data were presented as Mean \pm SEM. 


\section{MC38 tumor}

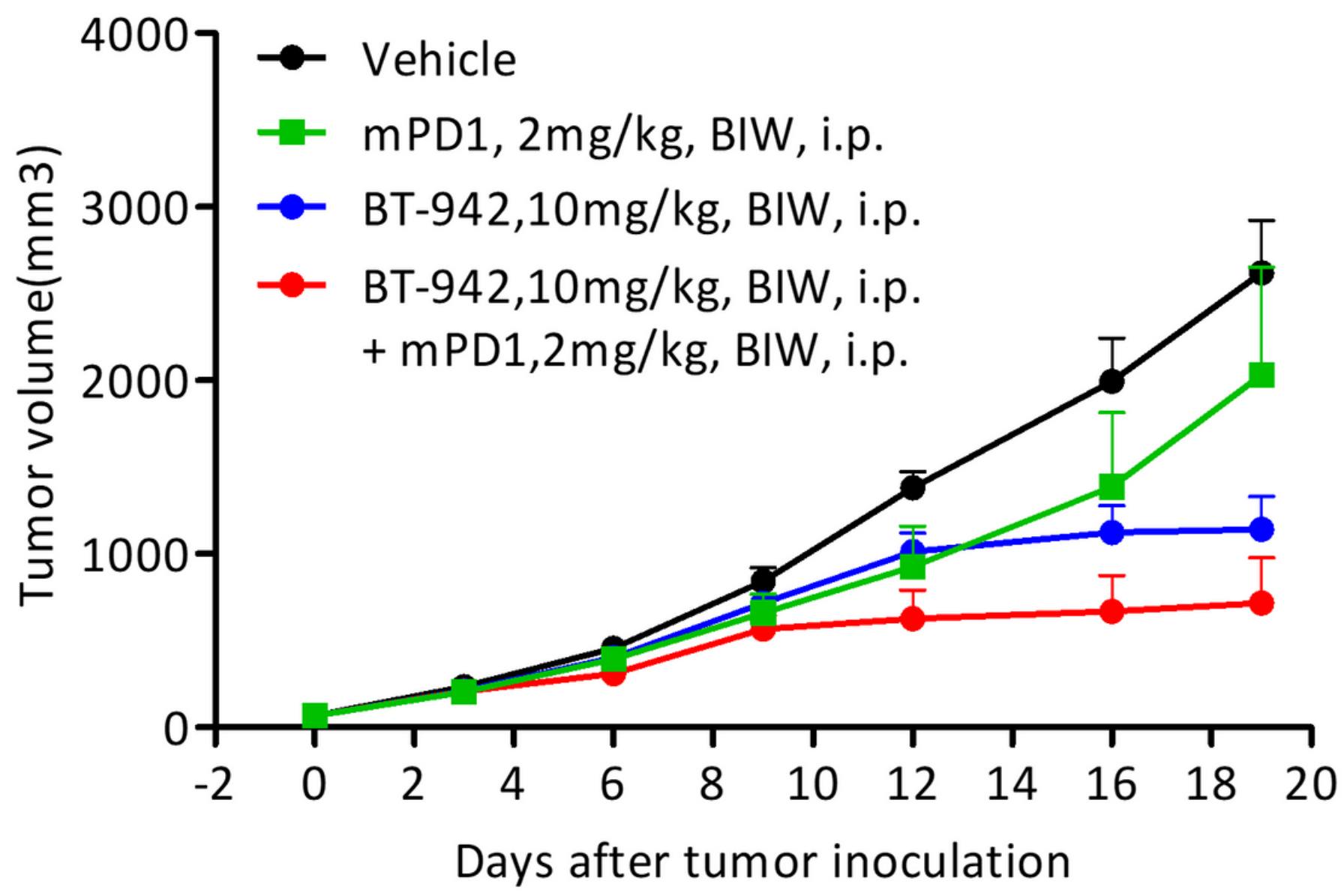

Figure 6

In vivo synergistic antitumor effect of combined BT942 with anti-mouse PD1 antibody. 

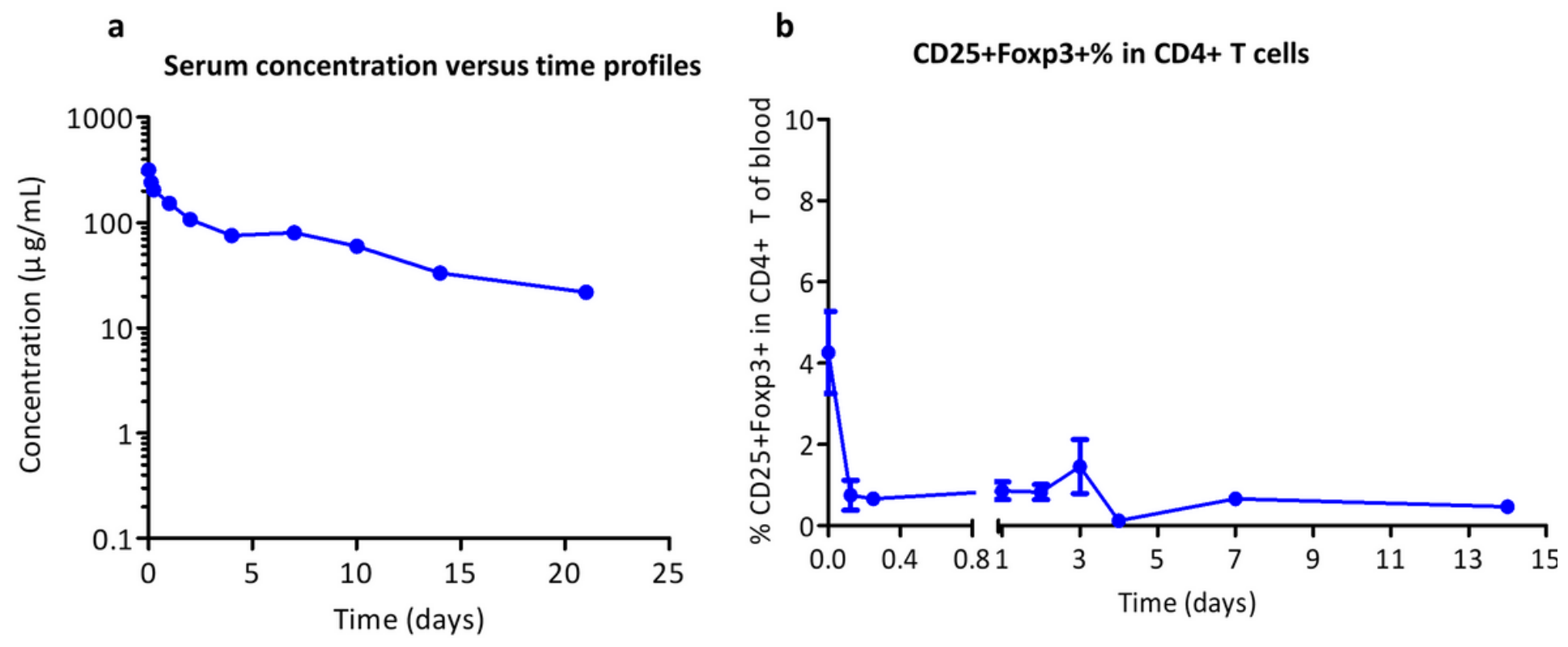

Figure 7

Pharmacokinetic and pharmacodynamic characteristics of BT942 in healthy cynomolgus monkeys. a. Two healthy cynomolgus monkeys were administered intravenously at a single dose of $10 \mathrm{mg} / \mathrm{kg}$ with BT942. Enzyme-linked immunosorbent assay (ELISA) was used to determine the concentration of BT942 in serum. ELISA experiment was performed in triplicate. The main PK kinetic parameters were calculated using Winnolin software. Data were presented as Mean \pm SEM. $b$. The peripheral blood before and after administration were collected from monkeys, and then the percentage of CD4+CD25+Foxp3+ cells in peripheral blood at different time points was detected with flow cytometry (CytomicsTM FC500). Data were presented as Mean \pm SEM.

\section{Supplementary Files}

This is a list of supplementary files associated with this preprint. Click to download.

- CD25mAbSupplementaryinformation.docx 